\title{
The Opportunistic approach to monetary policy and financial market conditions
}

\author{
Ndahiriwe Kasaï \\ Department of Economics, University of Pretoria, South Africa ${ }^{1}$ \\ and \\ Ruthira Naraidoo \\ Department of Economics, University of Pretoria, Pretoria 0002, South Africa \\ e-mail: ruthira.naraidoo@up.ac.za \\ Phone: +27 12 420-3729
}

November 2011

\begin{abstract}
We test the concept of the Opportunistic Approach to monetary policy in South Africa post 2000 inflation targeting regime. The paper contributes to the current debate on central banks having additional objectives over and above inflation and output by incorporating a measure of financial conditions in the modelling framework. Our findings support the two features of the opportunistic approach. First, we find that the models that include an intermediate target that reflects the recent history of inflation rather than simple inflation target improve the fit of the models. Second, the data supports the view that the South African Reserve Bank (SARB) behaves with some degree of nonresponsiveness when inflation is within the zone of discretion but react aggressively otherwise. Recursive estimates from our preferred model reveal that overall there has been a subdued reaction to inflation, output and financial conditions amidst the increased economic uncertainty of the 20072009 financial crisis.
\end{abstract}

Keywords: monetary policy, opportunistic approach, intermediate inflation, financial conditions JEL: C51; C52; C53 E52; E58

\footnotetext{
${ }^{1}$ Ndahiriwe Kasaï has been a graduate student at Department of Economics, University of Pretoria.
} 


\section{Introduction}

We provide a test of the opportunistic approach to monetary policy as originally developed by Orphanides and Wilcox (2002) and put to the data firstly by Martin and Milas (2010a) in the context of the US economy. The theoretical foundations provided by Orphanides and Wilcox (2002) assume that monetary policy is set depending on a 'zone of inaction'. 'Accordingly, the literature suggests that when inflation is within the zone, the focus of the central bank is on output rather than inflation stabilization (see Orphanides and Wilcox (2002)) $)^{3}$. In their contribution to the topic, Bomfim and Rudebusch (2000) judge that though opportunistic strategy may be able to achieve disinflation at a lower cost, it can probably take longer to achieve price stability than a deliberate approach. Bomfim and Rudebusch (2000) consider that "the opportunistic policymaker takes no deliberate action to reduce inflation further, but waits to exploit recessions and favorable supply shocks to lower inflation. When inflation gets pushed down by a shock, the interim inflation target is reset to equal the new prevailing lower rate, and, in this fashion, price stability is eventually achieved'. From this statement, the two features of the opportunistic approach emerge clearly.

The first feature is related to the concept of the zone of discretion for which policymakers are supposed to behave opportunistically by accommodating shocks that tend to move inflation towards the desired level. By contrast, it is argued that policymakers should react when inflation tends to move away from the desired level. The interest rate will be raised when inflation is above the zone of discretion and decreased if inflation is below the zone. The second feature is that monetary policy should move inflation toward an intermediate inflation resulting from inflation target and previous actual inflation rates. This feature of intermediate inflation is based on the idea that the central bank should not pursue a target for inflation that is too ambitious in the short run but, it should instead pursue a practical target for inflation that is within the grasp of the short term. This is particularly relevant for developing countries which might be more concerned about the inflation-output trade-off in the short-run.

The recent financial crisis has provided an additional challenge to simple Taylor rule models. For instance, amongst others, De Grauwe (2007) argues that asset prices should figure out as an objective for the central bank whereas Federal Reserve governor Mishkin (2008) and Federal Reserve Chairman Bernanke and Gertler (2001) argue for the converse. We follow previous works by Naraidoo and Raputsoane (2010) and Kasai and Naraidoo (2012) who find that the SARB has been reacting to financial conditions and that the inclusion of a financial conditions index in the reaction function improves the fit of the model. This motivation follows

\footnotetext{
${ }^{2}$ In fact, asymmetries resulting from a framework of target range of inflation can be described as a necessary condition for an opportunistic monetary policy but not as a sufficient one.

${ }^{3}$ A somewhat different theoretical model is provided by Minford and Srinivasan (2006) for this same concept.
} 
from works by Rudebusch (2002) who raises the issue of an omitted variables problem by pointing out that the significance of interest rate persistence in the policy rule could be due to omitting a financial spread variable from the estimated regression. Gerlach-Kirsten (2004) and English et al. (2003) find that inclusion of a financial spread reduces the empirical importance of interest rate smoothing (amongst others, Estrella and Mishkin (1997) analyze the influence of a term structure variable in policy rules). The concern that Central Banks should have additional objectives (and instruments) is gaining momentum (Walsh, 2009). For instance, ECB Vice President Papademos (2009) re-iterates that ECB aims at safeguarding financial stability in addition to achieving price stability.

Our contribution in this paper on top of investigating nonlinearity in monetary policy rules (see Altavillao and Landolfo (2005) for some recent evidence) in the context of whether the monetary policy reaction function for the (SARB) could express the consistency of the opportunistic approach is to augment such framework with a more comprehensive financial index variable that pools together relevant information provided by a number of financial variables. Inclusion of the financial index is based on the assumption that if fluctuations in financial markets cause welfare losses to the consumer, then stability of financial markets will figure in the loss function of the central banker (Walsh, 2009). Furthermore, the main model is estimated over expanding windows of data. Recursive estimation provides significant information on how the response coefficients to inflation, output gap and financial conditions have varied across times and across regimes (within and outside the zone of discretion) with the oncoming of the sub-prime crisis.

The remainder of the paper proceeds as follows. Section 2 outlines the model of Orphanides and Wilcox (2002) and Aksoy et al. (2006) and motivates the inclusion of financial conditions in the framework and we suggest how it might be estimated. Section 3 talks about the data. Section 4 discusses findings. Section 5 provides concluding remarks.

\section{Model specification}

We use the model of Orphanides and Wilcox (2002) with the added feature of the inclusion of financial conditions a la Martin and Milas (2010b). ${ }^{4}$ As such, unlike the conventional loss function, the loss function in this paper reflects a concern with financial stability by including a measure of domestic financial stability $(f)$. The inclusion of the financial index is based on the

\footnotetext{
${ }^{4}$ Martin and Milas (2010b) develop a flexible theoretical model to allow for changes in the preferences of policymakers when there is a financial crisis.
} 
assumption that policymakers have preferences for this index being close to equilibrium reflecting their desire to stabilise the financial system. Martin and Milas (2010b) discuss a theoretical model in which stability of the financial system enters the loss function of the policymakers. As in Martin and Milas (2010b), equation (4) assumes that financial stability can be increased by reducing nominal interest rates, allowing financial institutions to re-capitalize at a lower cost.

$$
\begin{aligned}
& \mathrm{L}=\left(\pi-\pi^{I}\right)^{2}+\gamma y^{2}+\kappa f^{2}+\psi \operatorname{abs}(y) \\
& \pi_{\mathrm{t}}=\pi^{e}+\alpha y_{t}+\varepsilon_{s t} \\
& y_{\mathrm{t}}=\alpha_{0}-\alpha_{r}\left(r_{t}-r^{*}\right)+\varepsilon_{d t} \\
& f_{t}=\bar{f}-\alpha_{f}\left(i_{t}-i^{*}\right)+\varepsilon_{f t}
\end{aligned}
$$

where $\pi$ is the inflation rate, $\pi^{I}$ is the intermediate inflation target, $y$ is the output gap, $f$ is the financial conditions index, $r$ is the real interest rate, $r *$ is the equilibrium real interest rate, $i$ is the nominal interest rate, $i^{*}$ is the equilibrium nominal interest rate, $\alpha_{s}$ are positive parameters, $\varepsilon_{s}$ is supply shock, $\varepsilon_{d}$ is a demand shock and $\varepsilon_{f t}$ is a financial shock. Equation (1) specifies the policymakers' loss function in terms of expected discounted sums of quadratic deviations of inflation from the inflation intermediate target, the loss from output comprises a conventional quadratic term and also a linear function of the absolute value of the output and the policymakers have preferences for $f$, the financial conditions index being close to equilibrium reflecting their desire to stabilise the financial system ${ }^{5}$. Equation (2) is a static expectations-augmented Phillips curve while equation (3) is a simple, static aggregate demand relationship.

Assuming that policy-makers choose the optimal interest rate for period $t$ at the end of period $t-1$ using information available up to the end of period $t-1$, Orphanides and Wilcox (2002) proposed the optimal monetary policy rule similar to equation (5) below. We note here that the inclusion of financial conditions in the model has led to an augmented monetary policy rule that reflects the concern by central banks over the maintenance of financial stability:

$$
i_{t}=i^{*}+\rho_{Z D} E_{t-1}\left(\pi_{t}-\pi_{t}^{I}\right)+\rho_{y} E_{t-1} y_{t}+\rho_{f} E_{t-1} f_{t} \quad \text { if }-\delta \leq E_{t-1}\left(\pi_{t}-\pi_{t}^{I}\right) \leq \delta
$$

\footnotetext{
${ }^{5}$ We provide a detailed explanation of how the financial conditions index is constructed in the data section.
} 


$$
\begin{array}{ll}
i_{t}=i^{*}+\rho_{\text {OZD }} E_{t-1}\left(\pi_{t}-\pi_{t}^{I}+\delta\right)+\rho_{y} E_{t-1} y_{t}+\rho_{f} E_{t-1} f_{t} & \text { if }-\delta>E_{t-1}\left(\pi_{t}-\pi_{t}^{I}\right) \\
i_{t}=i^{*}+\rho_{O Z D} E_{t-1}\left(\pi_{t}-\pi_{t}^{I}-\delta\right)+\rho_{y} E_{t-1} y_{t}+\rho_{f} E_{t-1} f_{t} & \text { if } \delta<E_{t-1}\left(\pi_{t}-\pi_{t}^{I}\right)
\end{array}
$$

The above nonlinear monetary policy rule comprises of three Taylor-like policy rules describing the reaction function of the policy-makers and it depends on whether expected inflation is below, within or above the zone of discretion. The zone ranges from $\delta$ percentage points below the intermediate inflation target to $\delta$ percentage points above. $\rho_{y}$ and $\rho_{f}$ are respectively the coefficient of output gap and financial conditions index. $\rho_{Z D}$ and $\rho_{O Z D}$ are respectively the coefficient of inflation within the zone of discretion and the coefficient of inflation outside the zone. If $\rho_{Z D} \neq \rho_{O Z D}$, it is an indication that the response by monetary policy makers depends on whether inflation is within the zone of discretion or not. By contrast, if $\rho_{Z D}=\rho_{O Z D}$, it is an indication that the monetary policy reaction function is linear and so equation (5) simplifies to the following equation:

$$
i_{t}=i^{*}+\rho_{\pi} E_{t-1}\left(\pi_{t}-\pi_{t}^{I}\right)+\rho_{y} E_{t-1} y_{t}+\rho_{f} E_{t-1} f_{t}
$$

Replacing the intermediate inflation target in equation (1) with the conventional point inflation target $\pi^{T}$, equation (6) becomes the usual Taylor (Taylor, 1993) rule model

$$
i_{t}=i^{*}+\rho_{\pi} E_{t-1}\left(\pi_{t}-\pi_{t}^{T}\right)+\rho_{y} E_{t-1} y_{t}+\rho_{f} E_{t-1} f_{t}
$$

Allowing for interest rate smoothing as in for e.g. Woodford (2003) we assume:

$$
i_{t}=\rho_{i}(L) i_{t-1}+\left(1-\rho_{i}\right) \hat{i}_{t}
$$

Where $\rho_{i}(L)=\rho_{i 1}+\rho_{i 2} L+\ldots+\rho_{i n} L^{n-1}$ is an indicator of the degree of smoothing of the instrument and $\hat{i}$ is the desired interest rate given by equation (7) above:

$$
\hat{i}_{t}=i^{*}+\rho_{\pi} E_{t-1}\left(\pi_{t}-\pi_{t}^{T}\right)+\rho_{y} E_{t-1} y_{t}+\rho_{f} E_{t-1} f_{t}
$$

Combining equation (8) and (9), solving for the expectation operator, $E$, and allowing for a forward looking version we have

$$
i_{t}=\rho_{i}(L) i_{t-1}+\left(1-\rho_{i}\right)\left\{i^{*}+\rho_{\pi}\left(\pi_{t+p}-\pi^{T}\right)+\rho_{y} y_{t+q}+\rho_{f} f_{t+r}\right\}+\varepsilon_{t}
$$

where $\varepsilon_{t}$ is an error term composed of expectational errors. As seen above, one of the opportunistic approach features is the use of intermediate inflation rather than simple inflation 
target. To allow for this feature, we rewrite equation (10) by replacing the inflation target by the intermediate inflation target to have

$$
i_{t}=\rho_{i}(L) i_{t-1}+\left(1-\rho_{i}\right)\left\{i^{*}+\rho_{\pi}\left(\pi_{t+p}-\pi^{I}\right)+\rho_{y} y_{t+q}+\rho_{f} f_{t+r}\right\}+\varepsilon_{t}
$$

where the intermediate inflation target is defined as

$$
\pi_{t}^{I}=\mu\left(\frac{1}{n} \sum_{j=1}^{n} \pi_{t-j}\right)+(1-\mu) \pi^{T}
$$

Equation (11) allows us to approximate the intermediate inflation target included in the standard Taylor rule. Note that the inflation target will not be identified as it is part of the constant ${ }^{6}$.

To test for the presence of opportunistic behavior, and so the presence of asymmetries, we define different regimes and allow for the possibility that the dynamic behavior of the monetary authority depends on whether inflation is lying within the target zone or not. As far as opportunistic approach is concerned, the model assumes two different regimes; namely the zone of discretion and the outside zone. Therefore, at this stage we consider the use of two-regime switching models. That is, the lower and upper boundaries of the target zone are regarded as the regime-determining processes. It is important to notice that the change from one regime to another can be abrupt or smooth. If the change is abrupt, then the non linear model will be of the following form

$$
\begin{array}{r}
i_{t}=\rho_{i}(L) i_{t-1}+\left(1-\rho_{i}\right)\left\{i^{*}+\rho_{Z D} E_{t-1}\left(\pi_{t+p}-\pi_{t+p}^{I}\right)+\rho_{y} E_{t-1} y_{t+q}+\rho_{f} E_{t-1} f_{t+r}\right\} \\
\text { if }-\delta \leq E_{t-1}\left(\pi_{t+p}-\pi_{t+p}^{I}\right) \leq \delta \\
\begin{array}{r}
i_{t}=\rho_{i}(L) i_{t-1}+\left(1-\rho_{i}\right)\left\{i^{*}+\rho_{O Z D} E_{t-1}\left(\pi_{t+p}-\pi_{t+p}^{I}+\delta\right)+\rho_{y} E_{t-1} y_{t+q}+\rho_{f} E_{t-1} f_{t+r}\right\} \\
\text { if }-\delta>E_{t-1}\left(\pi_{t+p}-\pi_{t+p}^{I}\right)
\end{array} \\
\begin{array}{r}
i_{t}=\rho_{i}(L) i_{t-1}+\left(1-\rho_{i}\right)\left\{i^{*}+\rho_{O Z D} E_{t-1}\left(\pi_{t+p}-\pi_{t+p}^{I}-\delta\right)+\rho_{y} E_{t-1} y_{t+q}+\rho_{f} E_{t-1} f_{t+r}\right\} \\
\text { if } \delta<\left(\pi_{t+p}-\pi_{t+p}^{I}\right)
\end{array}
\end{array}
$$

However, it is more likely to experience a smooth change from one regime to another. In that case, a so called Smooth Transition Autoregressive (STAR) model is appropriate:

\footnotetext{
${ }^{6}$ Martin and Milas (2010a) have noted this feature previously.
} 


$$
\begin{gathered}
i_{t}=\rho_{i}(L) i_{t-1}+\left(1-\rho_{i}\right)\left\{i^{*}+\rho_{Z D} E_{t-1}\left(\pi_{t+p}-\pi_{t+p}^{I}\right)+\rho_{y} E_{t-1} y_{t+q}+\rho_{f} E_{t-1} f_{t+r}\right\} \\
\operatorname{pr}\left\{-\delta \leq E_{t-1}\left(\pi_{t+p}-\pi_{t+p}^{I}\right) \leq \delta\right\} \\
i_{t}=\rho_{i}(L) i_{t-1}+\left(1-\rho_{i}\right)\left\{i^{*}+\rho_{O Z D} E_{t-1}\left(\pi_{t+p}-\pi_{t+p}^{I}+\delta\right)+\rho_{y} E_{t-1} y_{t+q}+\rho_{f} E_{t-1} f_{t+r}\right\} \\
\operatorname{pr}\left\{-\delta>E_{t-1}\left(\pi_{t+p}-\pi_{t+p}^{I}\right)\right\} \\
i_{t}=\rho_{i}(L) i_{t-1}+\left(1-\rho_{i}\right)\left\{i^{*}+\rho_{O Z D} E_{t-1}\left(\pi_{t+p}-\pi_{t+p}^{I}-\delta\right)_{+\rho_{y} E_{t-1} y_{t+q}+\rho_{f} E_{t-1} f_{t+r}}\right\} \\
\operatorname{pr}\left\{\delta<E_{t-1}\left(\pi_{t+p}-\pi_{t+p}^{I}\right)\right\}
\end{gathered}
$$

We model the probabilities in (14) using the logistic functions (see e.g. van Dijk et al., 2002)

$$
p r\left\{-\delta>E_{t-1}\left(\pi_{t+p}-\pi_{t+p}^{I}\right)\right\}=1-\frac{1}{1+e^{-\left\{E_{t-1}\left(\pi_{t+p}-\pi_{t+p}^{I}+\delta\right) / \sigma_{E_{t-1}}\left(\pi_{t+p}-\pi_{t+p}^{I}\right)\right.}}
$$

and

$$
\operatorname{pr}\left\{\delta<E_{t-1}\left(\pi_{t+p}-\pi_{t+p}^{I}\right)\right\}=\frac{1}{1+e^{-\mathfrak{x}_{t-1}\left(\pi_{t+p}-\pi_{t+p}^{l}-\delta\right) / \sigma_{E_{t-1}\left(\pi_{t+p}-\pi_{t+p}^{I}\right)}}}
$$

In (15a, b) we follow Granger and Teräsvirta (1993) and Teräsvirta (1994) in making the smoothness parameter $\gamma>0$ dimension-free by dividing it by the standard deviation of $E_{t-1}\left(\pi_{t+p}-\pi_{t+p}^{I}\right)$. In equation (14) it is assumed that the policy maker responds to $E_{t-1}\left(\pi_{t+p}-\pi_{t+p}^{I}+\delta\right)$ when inflation is below the zone of discretion and to $E_{t-1}\left(\pi_{t+p}-\pi_{t+p}^{I}-\delta\right)$ when the inflation is above the zone of discretion. As an alternative to (14), equation (16) assumes that the policymaker responds to $E_{t-1}\left(\pi_{t+p}-\pi_{t+p}^{I}\right)$.

$$
i_{t}=\rho_{i}(L) i_{t-1}+\left(1-\rho_{i}\right)\left\{\begin{array}{l}
i^{*}+\rho_{y} E_{t-1} y_{t+q}+\rho_{f} E_{t-1} f_{t+r}+\theta_{t} \rho_{Z D} E_{t-1}\left(\pi_{t+p}-\pi_{t+p}^{I}\right) \\
+\left(1-\theta_{t}\right) \rho_{\text {OZD }} E_{t-1}\left(\pi_{t+p}-\pi_{t+p}^{I}\right)
\end{array}\right\}+\varepsilon_{t}
$$

where $\theta=\operatorname{pr}\left\{-\delta \leq E_{t-1}\left(\pi_{t+p}-\pi_{t+p}^{I}\right) \leq \delta\right\}$ is the probability that the economy is within the zone of discretion. In equation (16) the response to inflation is contingent on whether inflation is within the zone of discretion. We model the probability of being within the zone using the quadratic logistic function (see, for example, van Dijk et al., 2002) 


$$
\theta=p r\left\{-\delta \leq E_{t-1}\left(\pi_{t+p}-\pi_{t+p}^{I}\right) \leq \delta\right\}=1-\frac{1}{1+e^{-\gamma\left[E_{t-1}\left(\pi_{t+p}-\pi_{t+p}^{I}+\delta\right)\right]\left[E_{t-1}\left(\pi_{t+p}-\pi_{t+p}^{I}-\delta\right)\right] / \sigma_{E_{t-1}\left(\pi_{t+p}-\pi_{t+p}^{I}\right)}^{2}}}
$$

Note that in equation (16), we have entered output and financial conditions linearly in the model. However, we have investigated whether there is a different response of interest rates to output and financial conditions inside and outside the zone of discretion. There was no evidence of these effects ${ }^{7}$.

\section{Data description}

We use South African seasonally adjusted data for the period spanning from January 2000 to December 2008. The beginning of the sample corresponds to the implementation of the official inflation targeting regime. The nominal interest rate is the repurchase rate (repo rate), inflation is the annual change in the consumer price index and output gap is measured as the log difference between industrial production ${ }^{8}$ and its Hodrick-Prescott (HP, 1997) trend. The financial index is constructed as an equal weighted average of (i) the real effective exchange rate $\left(R E E R_{t}\right)$ where the rand appreciation increases the index; (ii) the house price index $\left(R H_{t}\right)$ compiled by the ABSA bank, deflated by the consumer price index; (iii) the stock price $\left(R S_{t}\right)$ which is measured by the Johannesburg Stock Exchange All Share index, deflated by the consumer price index; (iv) the credit spread $\left(C S_{t}\right)$ which is the spread between the yield on the 10-year government bond and the yield on A rated corporate bonds; and (v) the future interest rate spread which is the change of spread between the 3 -month interest rate futures contracts $\left(F_{t}\right)$ in the previous quarter and the current short-term interest rate.

The real effective exchange rate, stock price and house price variables are de-trended by a HP filter. To tackle the end-point problem in calculating the HP trend (see Mise et al., 2005a, b), we applied an autoregressive $(\operatorname{AR}(n))$ model (with $n$ set at 4 to eliminate serial correlation) to the output measure and the components of the financial index. The AR model was used to forecast twelve additional months that were then added to each of the series before applying the HP

\footnotetext{
7 These results are available from the authors upon request. Similar conclusions have been found by Kasai and Naraidoo (2012) and Naraidoo and Raputsoane (2010) in the context of financial market conditions whereby the monetary authorities place an equal weight on financial market booms and recessions.

8 We also note that output can be measured using the coincident business cycle indicator computed by the SARB and we have provided robustness checks in Table 3, investigating the effect of this alternative measures of the output gap (measured as the deviation of this from a Hodrick-Prescott (1997) trend. In this paper, industrial production seems to give a better explanation of the behavior of the SARB.
} 
filter. The constructed financial index is expressed in standardised form, relative to the mean value of 2000 and where the vertical scale measures deviations in terms of standard deviations; therefore, a value of 1 represents a 1-standard deviation difference from the mean. Additionally, all data are seasonally adjusted. The index is also in the spirit of the UK financial conditions index provided by the Bank of England's Financial Stability Report (Bank of England, 2007). The financial index variable considered in our paper pools together relevant information provided by a number of financial variables as in Castro (2011). ${ }^{9}$

On the weights used in the financial conditions index, the approach in the paper has been to use an equal weighted average. In the literature, there has been few ways: a weightedsum approach, time-varying weights and a principal-components approach. We have also tried with time-varying weights using the method of Castro (2011) who performs Kalman Filter algorithm on the extended Rudebush and Svensson's (1999) IS equation. We prefer the choice of equal weight given that the time-varying weights are based on a backward-looking Phillips and IS curves, quite distinct from the model of the economy that we assumed in the paper. The measure with constant equal weights provides more meaningful results than the one with time varying weights.

The evolution of the main variables is shown in Figure $1^{10}$. The inflation rate is showing a persistent increase towards the end of the sample together with an accompanying increase in interest rate. The output gap is showing a severe downturn by the end of 2008. Movements in the financial index have a similar pattern to the interest rate which indicates a close link between the two variables, particularly towards the end of the sample. The variable particularly tracks the main milestones in the South African financial sector. Its turning points, particularly the downturns, are consistent with the technology market bubble in 2000, the September 11 terrorist attacks in the United States and the rapid depreciation of the South African currency in 2001, the US attack on Iraq in 2003 and the onset of the financial crisis via the subprime crisis in late 2007 and the collapse of the global financial market in late 2008 due to the bankruptcy of Lehman brothers. The volatility in 2003-2004 reflects the tight liquidity conditions due to high interest rates and low economic sentiment in emerging economies consistent with the war in Iraq in 2003 and the ultimate rally in financial markets as the tide of stringent liquidity conditions turned and

\footnotetext{
${ }^{9}$ See Castro (2011) for an in-depth discussion of this index.

${ }^{10}$ We have done some analysis of stationarity and this suggests that the inflation series follows a nonstationary process. ADF and PP unit root tests do not reject the null with p-values of around 0.13. However, in line with common practice, inflation is treated as stationary in our study. (See Fuhrer and Moore 1995, for discussion of similar issues).
} 
investor sentiment towards emerging economies improved in 2004. Descriptive statistics are reported in Table 1.

\section{Empirical results}

\subsection{Tests and parameter estimates}

The specification which fits the data best allows for one lag of the interest rate, $p=1$ for inflation, $q=1$ for the output gap, and $r=1$ for the financial index. The set of instruments includes a constant, lagged values of inflation, the output gap, the financial index, the 10-year government bond and M3 growth. Our empirical models that exclude the financial index variable performed very poorly compared to the models reported here in terms of the AIC criterion and the lagged interest rate effect turned out to be slightly higher than the one reported here, therefore providing some support for an omitted variables problem as outlined in the introduction. Each case reveals strong evidence that the SARB has been reacting to financial conditions index since the null hypothesis $H_{0}: \rho_{f}=0$ is rejected at $1 \%$ level of significance. Column (i) of Table 2 represents estimates of equation (10), the linear Taylor rule model. We find that $\rho_{i}=0.89, \rho_{\pi}=0.84, \rho_{y}=1.06$ and that $\rho_{f}=1.10$. This particular model does not comply with the Taylor principle which stipulates that the response to inflation is expected to be in greater proportion than the variation of inflation. ${ }^{11}$

The second step is estimation of equation (11) which uses intermediate inflation rather than simple inflation target. Intermediate inflation target at period $t$, is computed as a weighted average of inflation target and historical inflation measured as an average of inflation of three previous months. We have also tried historical inflation measured as averages of 1-6, 9 and 12 months but none of these alternatives could outperform the average of three months. Findings in column (ii) of Table 2 show that the substitution of inflation target by intermediate inflation target is supported by the data. In terms of AIC the model in column (ii) does better than the model in column (i). Furthermore, it is worth noting that $\mu$, the weight on past inflation is estimated at $\mu=0.33$ and is statistically significant. This is evidence that intermediate inflation reveals the behavior of the policy makers of the SARB better than simple inflation target. Therefore, one of the features of opportunistic approach to monetary policy is met.

\footnotetext{
${ }^{11}$ Similar results of inflation effect being lower than one for the case of South Africa has been noted by Woglom (2003) and Naraidoo and Gupta (2010).
} 
The third step is to test the consistency of the feature regarding zone of discretion. In doing so, both linear models, equation (10) in column (i) and equation (11) in column (ii), are subjected to tests of linearity. The $\lambda$ test by Hamilton (2001) and $\lambda_{A}$ and $g$ tests by Dahl and González-Riviera (2003) reject the null hypothesis of linearity. ${ }^{12}$ We then provide estimates of the TAR model (equation (13)) in column (iii) of Table 2. We find that $\delta=1.81$ and that the model performs better than the linear models presented in column (i) and (ii).

The fourth step is aimed at comparing the non linear models, namely equation (13), (14) and (16). With the aim to reduce the number of parameters to be estimated in equations (14) and (16) we set $\mu=0.33$ as suggested by model (11) above and $\delta=1.81$ as estimated in column (iii). Results of model (16) in column (v) exhibits lower standard error and better AIC than any other model we have estimated ${ }^{13}$. Therefore, we prefer this model for further investigations regarding parameter evolution in the next section. Estimation reveals that the null hypothesis of $\rho_{Z D}=0$ is not rejected while the null of $\rho_{\text {OZD }}=0$ is rejected. Therefore, the preferred model supports the view that monetary policymakers of the SARB have behaved opportunistically by accommodating shocks when inflation is within the zone of discretion but reacting aggressively otherwise. From the outperforming model (16) in column (v) we report that $\rho_{y}>\rho_{Z D}=0$ and that $\rho_{f}>\rho_{Z D}=0$. These results indicate that the SARB turns its attention to output gap and financial conditions when inflation is reported to be within the zone of discretion. This outperforming model reveals that the zone of discretion is symmetrically extending from 1.81 percent below and above the intermediate inflation rate. Estimated zone of discretion of 3.62 percent is reasonable for the SARB as the difference between the announced lower bound and upper bound is 3 percent. Taking the official target range of 3 to 6 percent as a benchmark to our estimate, we can suggest that estimated target zone spans from 2.69 to 6.31 percent. $^{14}$

12 We run the tests using Gauss codes obtained from Hamilton's web page at: http://weber.ucsd.edu/ jhamilto/software.htm\#other. To account for the small sample, we report bootstrapped $p$-values of the three tests based on 1000 re-samples.

${ }^{13}$ We have conducted a series of robustness checks, investigating the effect of alternative measures of the output gap. Our results are robust to these alternative specifications as shown in Table 3. We have estimated models based on four alternative measures of output gap for equation (16); namely output gap using industrial production (the one in the main text), output gap using the coincident business cycle indicator (measured as the deviation of this from a Hodrick-Prescott (1997) trend) and the annual growth rates of these variables. The SARB provides measures of the coincident business cycle indicator and it is made publicly available. In this paper, the model with industrial production provides better AIC.

${ }^{14}$ As a robustness check, we have assessed the sensitivity of our findings to alternative data definitions, viz., several measures of the output gap and alternative model specifications to assess the usefulness of the financial index. These 


\subsection{Recursive estimates}

To obtain an idea of how the response parameters $\rho_{O Z D}, \rho_{y}$, and $\rho_{f}$ evolve over time, Figure 2 plots the recursive estimates (plus/minus $2 *$ standard errors) over expanding data windows for our preferred model; equation (16). The response to inflation is relatively stable up until August 2007. From February 2008 onward, the Taylor principle does not hold as the coefficient is slightly less than unity. The response to the output gap is relatively unstable early 2006 but has started declining consistently only toward the third quarter of 2007. However, it should be kept in mind that Orphanides and van Norden (2002) have suggested the use of real time data in monetary policy since data used to compute output gap are subject to significant revisions. A possible explanation of our findings is that the magnitude of the response using final data for the output gap could suffer from downward bias owing to the errors-in-variables problem. Panel (c) in figure 2 reveals a more volatile response to financial index increasing from 0.56 early in 2006 to 1.00 late in 2007. Since then, the response to financial conditions decreased significantly until it reaches 0.36 in the third quarter of 2008 . This relatively more frequent volatility advocates in favor of the concern raised by Bernanke and Gertler (2001) and Filardo (2000) about the potential costs of responding to asset price given its volatility relative to their information content. Overall, the 2007-2009 financial crisis witnesses an overall decreased reaction to inflation, output and financial conditions. A plausible explanation is that the authority was faced with high uncertainty over evolving economic conditions with the oncoming recession, having gone through a period of prolonged boom recently.

\section{Conclusion}

With the aim to test whether the SARB's monetary policy makers have behaved opportunistically, we have estimated monetary policy reaction function for the period spanning from 2000M1 to 2008M12. We first test whether monetary policy makers of the SARB have been using intermediate inflation target rather than simple inflation target. The equations that include intermediate rather than simple inflation target improve the fit of the models. For linear models we use tests for linearity and find that the null of linear model is rejected by the data. In

results are widely discussed and analysed in a working paper version of this paper, see Kasai and Naraidoo (2011). In this paper, we report the best results obtained. 
addition, we test whether policy makers have been responding aggressively to inflation when it is outside the zone of discretion but accommodating the shock when inflation is within the target zone. We compare different linear and non linear models and find that a smooth transition model, supporting the view of opportunistic approach, fits the data better. Our augmented monetary policy rules with financial index perform better than any model that abstracts from financial index.

In our preferred model, we find that the zone of discretion is symmetric, extending from 1.81 percent below and above the intermediate inflation rate. Estimated inflation target range of 3.62 percent is reasonable for the SARB as the difference between the announced lower bound and upper bound is 3 percent. Taking the official target range of 3 to 6 percent as a benchmark to our estimate, we can suggest that the estimated target zone spans from 2.69 to 6.31 percent.

With the aim to appraise how monetary policy makers have behaved during the subprime crisis, we have also assessed parameter evolution of the preferred model by recursive estimation of the data window adding one data point at each time. We find that in general the 2007-2009 financial crisis witnesses an overall decreased reaction to inflation, output and financial conditions amidst uncertainty of the oncoming recession, having gone through a boom recently.

There are a number of findings worth mentioning. The models that include intermediate rather than simple inflation target improve the fit of the models. Among linear and nonlinear models, a quadratic logistic function outperforms all other models and provides support that monetary policymakers of the SARB have behaved opportunistically by accommodating shocks when inflation is within the zone of discretion but reacting aggressively otherwise. The outperforming model reveals that the zone of discretion is symmetrically extending from 1.81 percent below and above the intermediate inflation rate. An estimated inflation target range of the magnitude of 3.62 percent is reasonable for the SARB as the difference between the pre announced lower bound and upper bound is 3 percent. Taking the official target range of 3 to 6 percent as a benchmark to our estimate, we can suggest that estimated target zone spans from 2.69 to 6.31 percent. We further use the preferred model to evaluate parameter evolution since January 2006. Recursive estimation reveals that in general, the 2007-2009 financial crisis witnesses an overall decreased reaction to inflation, output and financial conditions amidst uncertainty over the oncoming recession, having gone through an extended booming period recently. 


\section{References}

Aksoy, Y., Orphanides, A., Small, D., Weiland, V. and Wilcox, D. (2006) A quantitative exploration of the opportunistic approach to disinflation, Journal of Monetary Economics, 53, 1877-1893.

Altavilla, C. and Landolfo, L. (2005) Do central banks act asymmetrically? Empirical evidence from the ECB and the Bank of England, Applied Economics, 37, 507-519.

Bank of England (2007) Financial Stability, Report 21 (April): 1-78.

Bernanke, B. and Gertler, M. (2001) Should Central Banks Respond to Movements in Asset Prices?" American Economic Review, 91, 253-257.

Bomfim, A.N. and Rudebusch, G.D. (2000) Opportunistic and Deliberate Disinflation under Imperfect Credibility, Journal of Money, Credit and Banking, 32, 707-721.

Castro, V. (2011) Can central banks' monetary policy be described by a linear (augmented) Taylor rule or by a nonlinear rule? Journal of Financial Stability, 7, 228-246.

Dahl, C.M. and González-Rivera, G. (2003) Testing for neglected nonlinearity in regression models based on the theory of random fields, Journal of Econometrics, 114, 141-164.

De Grauwe, P. (2007) Central banks should prick asset bubbles, The Financial Times, Thursday, Nov 1, 2007.

English, W.B., Nelson, W.R. and Sack, B.P. (2003) Interpreting the significance of the lagged interest rate in estimated monetary policy rules, Contributions to Macroeconomics, 3, Article 5.

Estrella, A. and Mishkin, F.S. (1997) The predictive power of the term structure of interest rates in Europe and the United States: Implications for the European Central Bank, European Economic Review, 41, 1375-1401.

Filardo, A.J. (2000) Monetary policy and asset prices", Economic Review, Federal Reserve Bank of Kansas City, 85, 11-37.

Fuhrer, J.C. and Moore, G.R. (1995) Inflation persistence, Quarterly Journal of Economics, 110, 127159.

Gerlach-Kristen, P. (2004) Interest-rate smoothing: monetary policy inertia or unobserved variables?" Contributions to Macroeconomics, 4, 1-17 
Granger, C.W.J., and Teräsvirta, T. (1993) Modelling nonlinear economic relationships, Oxford University Press, Oxford.

Hamilton, J.D. (2001) A parametric approach to flexible nonlinear inference, Econometrica, 69, $537-573$.

Hansen, L.P. (1982) Large Sample Properties of Generalized Method of Moments Estimators, Econometrica, 82, 1029-1054.

Hodrick, R.J. and Prescott, E.C. (1997) Postwar U.S. business cycles: An empirical investigation", Journal of Money, Credit, and Banking, 29, 1-16.

Kasai, N. and Naraidoo, R. (2011) The Opportunistic approach to monetary policy and financial market conditions, Working paper No 2011-03, Department of Economics, University of Pretoria, Available from: http://web.up.ac.za/sitefiles/file/40/677/WP 2011 03.pdf.

Kasai, N. and Naraidoo, R. (2012) Financial asset prices, linear and nonlinear policy rules. An Insample assessment of the reaction function of the South African Reserve Bank, Working paper in economics No 2010-06, University of Pretoria, Pretoria (Forthcoming in Journal of Economic Studies).

Martin, C. and Milas, C. (2010a) Testing the opportunistic approach to monetary policy, The Manchester School, 78, 110-125.

Martin, C. and Milas, C. (2010b) The Sub-Prime Crisis and UK Monetary Policy, International Journal of Central Banking, 6, 119-144.

Minford, P. and Srinivasan, N. (2006) Opportunistic monetary policy: An alternative rationalization, Journal of Economics and Business, 58, 366- 372.

Mise, E., Kim, T-H. and Newbold, P. (2005a) On the Sub-Optimality of the Hodrick-Prescott Filter, Journal of Macroeconomics, 27, 53-67.

Mise, E., Kim, T-H. and Newbold, P. (2005b) Correction of the Distortionary end-effect of the Hodrick-Prescott Filter: Application, Mimeo. Available from:

http://www.le.ac.uk/economics/staff/em92.html.

Mishkin, F.S. (2008) How Should We Respond to Asset Price Bubbles? Speech at the Wharton Financial Institutions Center and Oliver Wyman Institute, Annual Financial Risk Roundtable, Philadelphia, Pennsylvania. Available from: 
http://www.federalreserve.gov/newsevents/speech/mishkin20080515a.htm

Naraidoo, R. and Gupta, R. (2010) Modelling Monetary Policy in South Africa: Focus on Inflation Targeting Era Using a Simple Learning Rule, International Business and Economics Research Journal, 9, 89-98.

Naraidoo, R. and Raputsoane, L. (2011) Zone targeting monetary policy preferences and financial market conditions: a flexible nonlinear policy reaction function of the SARB monetary policy, South African Journal of Economics, 78, 400-417.

Orphanides, A. and Wilcox, D. (2002) The opportunistic approach to disinflation, International finance, 5, 47-71.

Orphanides A. and van Norden, S. (2002) The Unreliability of Output-Gap Estimates in Real Time, The Review of economics and statistics, 84, 569-583.

Papademos, L. (2009) Monetary policy and the 'Great Crisis': Lessons and challenges. Speech at the Conference "Beyond the Crisis: Economic Policy in a New Macroeconomic Environment", Vienna, 14 May 2009. Available from:

http://www.ecb.int/press/key/date/2009/html/sp090514.en.html.

Rudebusch, G.D. (2002) Term structure evidence on interest rate smoothing and monetary policy inertia, Journal of Monetary Economics, 49, 1161-1187.

Rudebusch, G. and Svensson, L. (1999) Policy rules for inflation targeting. In Monetary Policy Rules, (Eds) J. B. Taylor, University of Chicago Press for NBER.

Taylor, J. (1993) Discretion versus policy rules in practice, Carnegie-Rochester Conference Series on Public Policy, 39, 195-214.

Teräsvirta, T. (1994) Specification, Estimation, and Evaluation of Smooth Transition Autoregressive Models, Journal of the American Statistical Association, 89, 208-218.

van Dijk, D., Teräsvirta, T. and Franses, P.H. (2002) Smooth transition autoregressive models a survey of recent developments, Econometric Reviews, 21, 1-47.

Walsh, C. (2009) Using monetary policy to stabilize economic activity. Financial Stability and Macroeconomic Policy, Federal Reserve Bank of Kansas City, Jackson Hole Symposium, 245-296. 
Woglom G. (2003) How has inflation targeting affected monetary policy in South Africa? South African Journal of Economics, 71, 198-210.

Woodford, M. (2003), Interest and prices: Foundations of a theory of monetary policy, Princeton University Press, Princeton. 
Table 1: Descriptive statistics of the main variables

\begin{tabular}{lccccccccc}
\hline & $i_{t}$ & $\pi_{t}$ & $y_{t}$ & $f_{t}$ & $\left(R E E R_{t}\right)$ & $\left(R H_{t}\right)$ & $\left(R S_{t}\right)$ & $\left(C S_{t}\right)$ & $\left(F_{t}\right)$ \\
& 9.98 & 5.87 & 0.32 & 0.10 & 0.14 & 0.09 & 0.13 & 1.23 & -0.04 \\
Mean & 10.00 & 5.40 & 0.26 & 0.11 & 0.49 & 0.47 & -0.11 & 1.21 & 0.02 \\
Median & 13.50 & 13.70 & 4.85 & 2.82 & 2.92 & 2.09 & 8.88 & 2.30 & 30.97 \\
Minimum & 7.00 & 0.20 & -4.24 & -3.26 & -4.20 & -3.28 & -13.31 & -1.33 & -29.50 \\
Std. Dev. & 2.14 & 3.32 & 1.91 & 0.90 & 1.43 & 1.40 & 4.65 & 0.43 & 8.26 \\
Skewness & 0.01 & 0.46 & 0.20 & -0.17 & -0.96 & -0.69 & -0.19 & -1.62 & 0.12 \\
Kurtosis & 1.61 & 2.69 & 3.00 & 4.45 & 3.77 & 2.57 & 2.90 & 13.28 & 5.19 \\
& & & & & & & & & \\
Jarque-Bera & 8.33 & 4.12 & 0.76 & 9.84 & 19.33 & 9.55 & 0.73 & 523.58 & 21.89 \\
Probability & 0.01 & 0.12 & 0.68 & 0.01 & 0.00 & 0.01 & 0.69 & 0.00 & 0.00 \\
\hline
\end{tabular}


Table 2: GMM estimates of the Opportunistic Approach on SA data, (2000:M1-2005:M12)

\begin{tabular}{|c|c|c|c|c|c|}
\hline & (i) & (ii) & (iii) & (iv) & (v) \\
\hline$\rho_{i}$ & $0.89(0.01)$ & $0.89(0.01)$ & $0.87(0.01)$ & $0.87(0.01)$ & $0.86(0.01)$ \\
\hline$\rho_{\pi}$ & $0.84(0.02)$ & $1.31(0.22)$ & & & \\
\hline$\rho_{Z D}$ & & & $0.71(0.28)$ & $-10.89(3.03)$ & $-0.58(0.43)$ \\
\hline$\rho_{O Z D}$ & & & $1.18(0.19)$ & $0.67(0.20)$ & $1.08(0.06)$ \\
\hline$\rho_{y}$ & $1.06(0.15)$ & $0.85(0.08)$ & $0.68(0.12)$ & $0.69(0.13)$ & $0.58(0.12)$ \\
\hline$\rho_{f}$ & $1.10(0.11)$ & $1.01(0.09)$ & $0.81(0.14)$ & $0.74(0.09)$ & $0.56(0.12)$ \\
\hline$\mu$ & & $0.33(0.08)$ & $0.18(0.11)$ & $0.33(0.08)$ & $0.33(0.08)$ \\
\hline$\delta$ & & & $1.81(0.41)$ & $1.81(0.41)$ & $1.81(0.41)$ \\
\hline S.E & 0.373 & 0.369 & 0.367 & 0.372 & 0.365 \\
\hline AIC & 0.944 & 0.920 & 0.936 & 0.938 & 0.897 \\
\hline $\mathrm{H}_{0}: \rho_{Z D}=\rho_{O Z D}(p$ value $)$ & & & 0.026 & 0.000 & 0.000 \\
\hline J-statistic & 0.222 & 0.234 & 0.225 & 0.228 & 0.220 \\
\hline$\lambda$ test ( $\not$ value $)$ & 0.001 & 0.01 & & & \\
\hline$\lambda_{A}$ test $(p$ value $)$ & 0.000 & 0.00 & & & \\
\hline$g$ test ( $\not$ value) & 0.001 & 0.01 & & & \\
\hline
\end{tabular}

Notes: Numbers in parentheses are standard errors. S.E is the regression standard error. AIC is Akaike Information criterion. J-statistic is the $p$-value of a chi-square test of the model's over-identifying restrictions (Hansen, 1982). The set of instruments includes a constant and 12 lagged values of the regressors included in the model. The table also reports bootstrapped $p$-values of the $\lambda$, $\lambda_{A}$, and $g$ tests based on 1000 re-samples. 

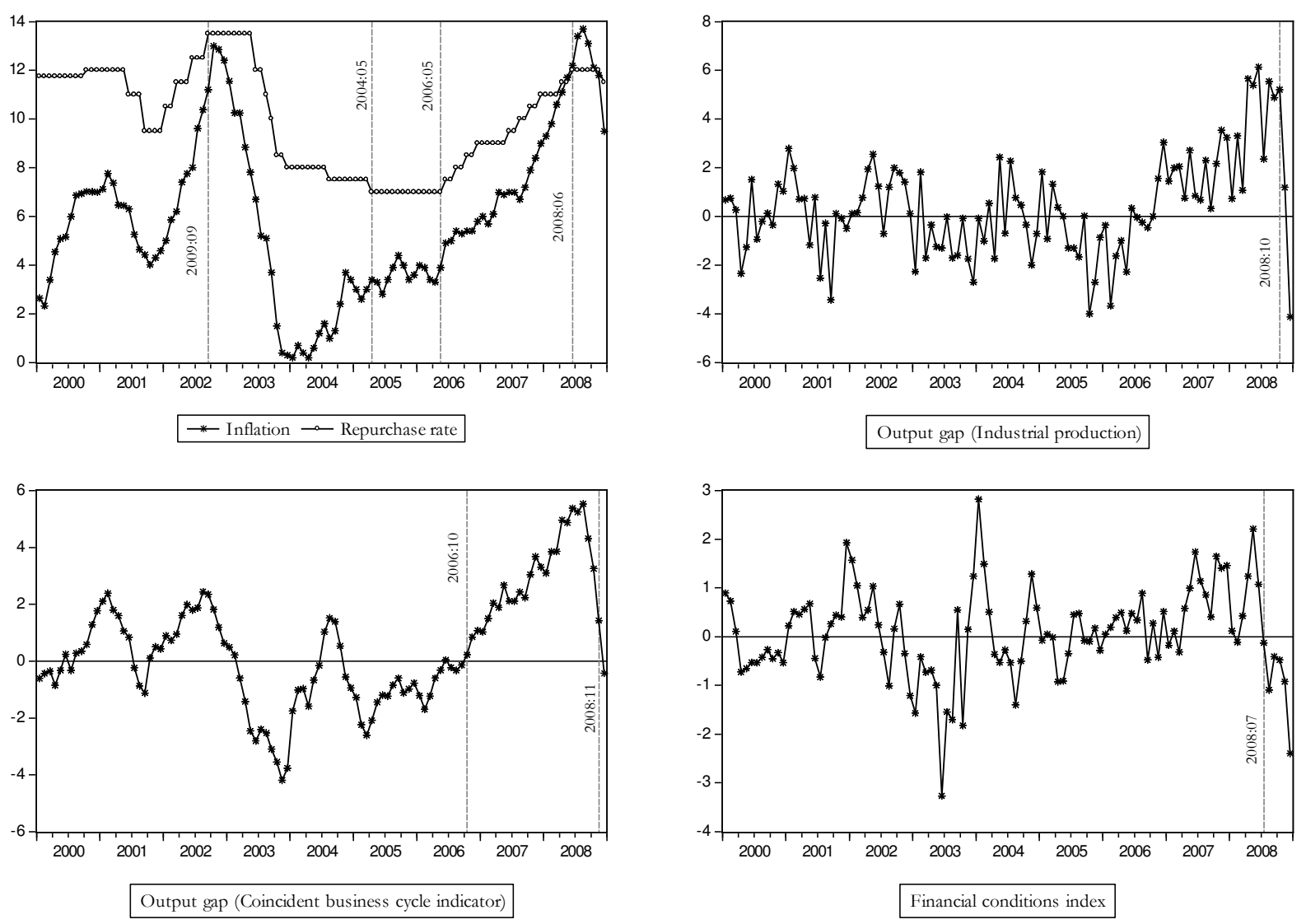

Figure 1: Interest rate, inflation, output measures and financial index 


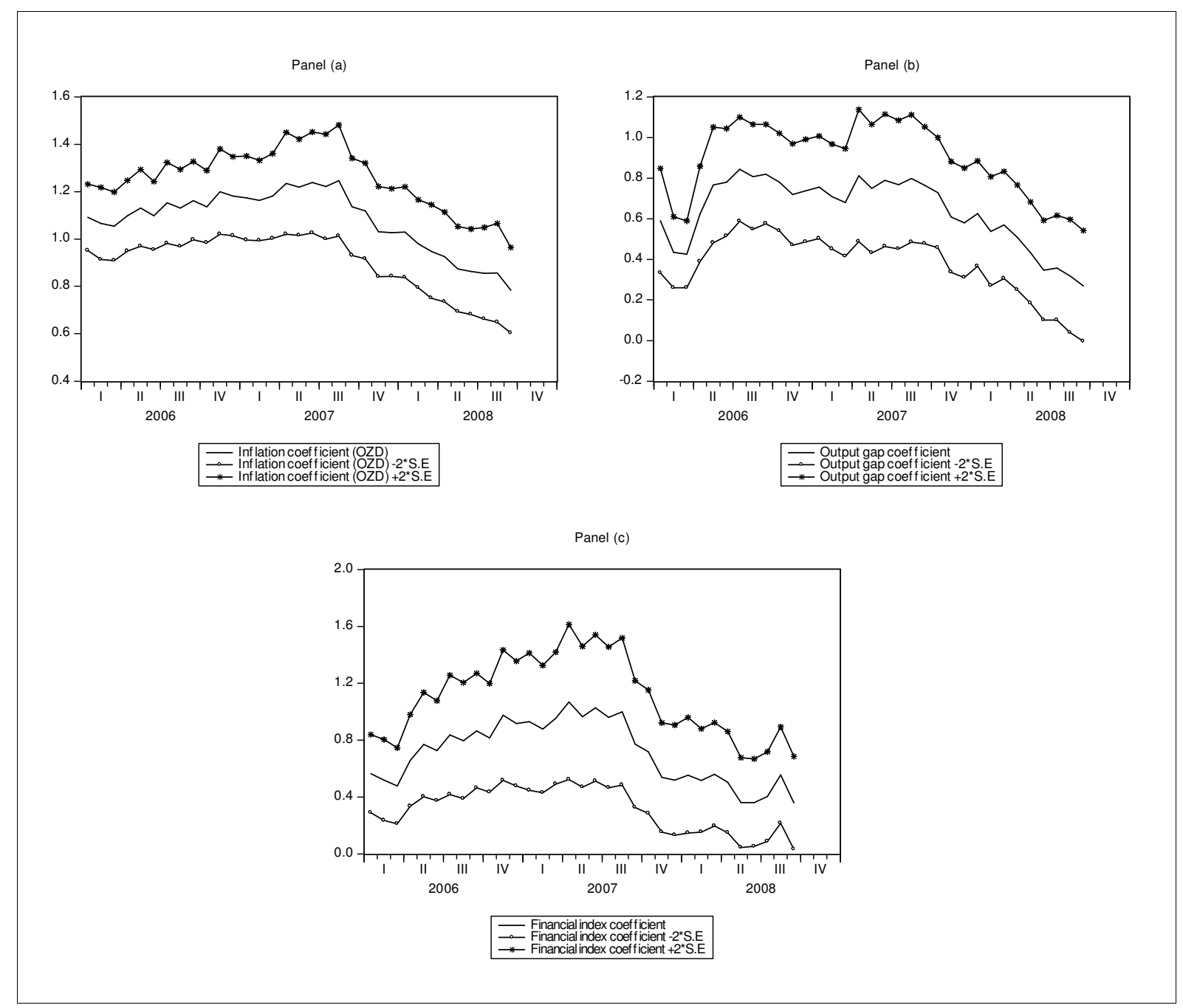

Figure 2: Recursive estimates 